\title{
Meeting Labour Market Needs for French as a Second Language Instruction in Ontario
}

\author{
David Jack ${ }^{1, *}$, Judith Nyman ${ }^{2}$ \\ ${ }^{1}$ FSL-Labour Market Partnership Project, Ontario Public School Boards’ Association, Toronto, Canada \\ ${ }^{2}$ Labour Market Partnership Project, Ontario Public School Boards’ Association, Toronto, Canada \\ *Corresponding author: DJack@opsba.org
}

Received April 11, 2019; Revised June 05, 2019; Accepted July 02, 2019

\begin{abstract}
Satisfying the demand for qualified French as a Second Language (FSL) teachers has been a persistent challenge in Ontario schools for many years. This article reports on research conducted with all publicly funded English-language school boards and hundreds of FSL teachers to better understand the recruitment, hiring and retention of such teachers. This research is part of a three-year project that involves multiple stakeholders in the FSL teacher supply pipeline collaborating to implement workable solutions to this long-standing issue.
\end{abstract}

Keywords: French as a Second Language teachers, recruitment, hiring, retention

Cite This Article: David Jack, and Judith Nyman, "Meeting Labour Market Needs for French as a Second Language Instruction in Ontario." American Journal of Educational Research, vol. 7, no. 7 (2019): 428-438. doi: 10.12691/education-7-7-1.

\section{Introduction}

Under the Education Act in Ontario, French language instruction is mandatory in publicly-funded schools, with students required to study the language for a period of six years from grades four through nine. School boards have the option to offer supplementary French as a Second Language (FSL) programs, such as French Immersion, based on local demand and resources.

Since the early 2000s, English-language public school boards across Ontario have been experiencing persistent challenges in recruiting and retaining teachers qualified to teach French as a Second Language programs in elementary and secondary schools. These challenges have been reported in the academic literature $[1,2,3,4,5]$, in reports by advocacy groups $[6,7,8]$, in recent program reviews by multiple school boards across the province, and by the Ontario Ministry of Education [9]. Recent Ministry of Education figures for the 2015-2016 school year indicated another rise in student enrolment in French Immersion in Ontario. The average annual growth rate of $5.7 \%$ province-wide has been sustained for eleven consecutive years.

The growing gap between the number of students enrolling in FSL programs and the availability of qualified teachers to do the job has been identified by the English-language school boards across the province and garnered ongoing media attention ([10,11]; public broadcaster TVO's The Agenda, [12]). Additionally, the chronic demand for FSL teachers has most recently been the subject of a number of public policy announcements by the Ontario provincial government (November, 2017) and Canadian federal government (February, 2018).

To this end, the Ontario Public School Boards' Association, representing public school board trustees, obtained a grant from the Ministry of Advanced Education and Skills Development to establish a Labour Market Partnership that included multiple stakeholder groups representing teacher unions, district school boards, university Faculties of Education, and related professional associations. This article reports on the research conducted during the first phase of the Partnership's three-year project.

\section{Project Scope}

A number of factors converge to create this labour market challenge each with different implications regarding potential solutions. Analyses from various stakeholders point to key factors such as overall increases in the demand for FSL education programs, (in particular, optional programs such as French Immersion), reduced numbers of qualified graduates from teacher education programs, attrition within the existing FSL teacher supply, and only modest success in recruiting qualified teachers from outside Ontario.

The present study aims to uncover the factors most affecting the FSL teacher supply pipeline by identifying two key objectives:

1. to study the supply and demand issues specifically related to the recruitment, hiring and retention of FSL teachers; and,

2. to develop and begin to implement recommendations towards workable solutions with key stakeholder groups. 
Step 1: Faculties of Education accept students into teacher education programs. Teachers can also earn Additional Qualifications in FSL during or following their initial teacher education program.
Step 2: Ontario College of Teachers grants required FSL credentials for teachers, including those educated outside Ontario
Step 3: School boards recruit and hire qualified FSL teachers based on anticipated need. This process can be influenced by local collective agreements and government regulation.
Step 4: FSL teachers begin teaching in FSL programs. Over time, teachers have opportunities to continue teaching FSL or to pursue other teaching assignments.

Figure 1. Steps in becoming an FSL teacher in Ontario

Figure 1 illustrates the entire pathway to becoming an FSL teacher in Ontario, the decision-making that governs various steps along this pathway, and the point at which school districts begin to recruit and hire.

\section{Literature Review}

Concerns about the availability of teachers able and willing to teach French as a Second Language programs underscore a curious paradox: with 1 in 5 Canadians claiming French as the first language, and nearly 18\% of Canadians claiming to be functionally bilingual in English and French (Statistics Canada, 2016), why is it increasingly difficult to supply schools with sufficient numbers of qualified teachers to teach French to willing learners?

There are several factors that weigh into this paradox. They include the uneven concentration of French speakers across the country, varying provincial requirements for students to study French, demand for French-speaking individuals in many other economic sectors, and ultimately, the hard-to-predict decisions people make in choosing a career path. Similarly challenging has been the time required for education systems to respond to the increasing demand for more French programs.

For more than a decade, issues specific to French teacher shortages have been documented by the Ontario College of Teachers, the professional regulatory body governing teacher qualifications. The Transition to Teaching Report, 2006 and The State of FSL Education in Canada report, published biennially by Canadian Parents for French, has discussed FSL teacher shortages in each issue since 2000. Academic research has also highlighted the shortage of FSL teachers in Ontario as early as the 1990s, [13] and more recently as a persistent challenge in expanding bilingualism efforts in Canada [1,5,14,15]. In turn, research has also linked FSL teacher shortages to other issues such as compromised language program standards [15]; restricted access to senior level subjects taught in French in secondary schools [16]; unfavourable working conditions [17], the impact of professional development opportunities [18], and has questioned the effectiveness of FSL teacher education programs [1].

Over time, much of the explored FSL research has focused on program outcomes and effective pedagogy, (e. g., how well students learn French in various second language settings), with the most relevant studies pointing to strong language learning and other positive scholastic outcomes, particularly in FSL programs such as French Immersion or Extended French. This research has fuelled, in part, a growing demand by parents to enrol their children in such programs [19], subsequently further increasing the demand for FSL teachers. Research has been less comprehensive in its understanding of the interplay between the necessary factors needed to provide a productive supply pipeline of FSL teachers in a growing market.

\section{Methodology}

The research plan of the project identified two key research questions:

1. Why do school boards find it challenging to recruit sufficient numbers of French teachers and support staff? and,

2. What strategies can be implemented by key stakeholders to satisfy the increasing market demand?

Three data sources were explored to help better understand the FSL teacher supply pipeline, and ultimately to inform project recommendations related to teacher recruitment, hiring and retention:

- a review of past studies and reports on FSL teacher recruitment, attrition, working conditions and policy implementation;

- qualitative and quantitative employment data from Ontario school districts' Human Resources (HR) departments, the Ontario College of Teachers, and the Ministry of Education to quantify the FSL teacher shortage and to understand related factors in different board contexts, e.g.,, rural, northern, urban; and,

- quantitative and qualitative data from recently hired FSL teachers regarding their experiences looking for work, being hired, and transitioning to the role of FSL teacher.

This latter data source has been largely missing in the current body of FSL teacher research so was considered an important link in understanding the current supplydemand landscape.

\subsection{Instrument Design and Analysis}

A two-part survey, French as a Second Language Teacher Hiring - HR Perspectives, was developed to gather recruitment and hiring data from Human Resources departments in all English-language school boards in Ontario. Survey items gathered quantitative information such as types of FSL programs offered, the overall number of FSL teacher positions required by boards and the 
number of FSL teacher applicants for the 2017-2018 academic year. Responses were tabulated based on overall numbers, averages across boards and the range of reported responses to create a picture of FSL teacher recruitment and hiring across the province. Qualitative data were also collected through open-ended questions following many survey items, as well as an open response item at the end of the survey. These comments were analysed for common themes using NVivo V12 analysis software and compared to relationships emerging from the quantitative data.

Additionally, an online survey, Recruiting, Developing and Retaining FSL Teachers, was distributed through boards' HR departments to FSL teachers newly hired in the past two years. The survey gathered both quantitative and qualitative data about the recruitment and hiring experiences of these teachers. Quantitative items included, for example, the number of interviews attended, components of the job application process, and type of FSL positions hired to in the past two years. Some items allowed responses to be tallied by frequency whereas other items generated weighted responses. Many survey items included open comment options. Respondents' comments were analysed for common themes and their relationship to quantitative responses.

First and second year FSL teachers were also invited to join focus groups to allow the collection of more nuanced data related to their recent recruitment and hiring experiences. Focus group responses were recorded and transcribed verbatim by the research assistant team, then analysed for common themes and compared to emerging themes in the related survey.

\section{Research Limitations}

The research conducted for the present study is limited in two ways. A few HR departments experienced technical challenges in providing accurate responses for all survey items due to changes in data management systems. In such cases, best estimates were provided. Second, the recruitment, hiring and transition to teaching experiences capture the circumstances of teachers in their first and second year only, and therefore cannot be said to represent the hiring experiences of teachers hired with more than two years of experience as FSL teachers.

\subsection{Key Findings - Perspectives from Human Resources}

The following section reports on findings from a twopart survey designed to capture the recruitment and hiring processes used by school boards to satisfy their respective need for FSL teachers in the past three years. The survey was distributed to all English-language school boards in Ontario. Fifty-six school boards (or 93\% of eligible boards) responded to the survey - as such their responses provide a reasonably accurate picture of the FSL teacher hiring landscape across the province.

The survey was organized in an effort to quantify three key questions:

- How do we understand FSL teacher demand?

- How do we understand FSL teacher supply? and,
- What do boards do to recruit FSL teachers and how effective are their strategies?

\subsection{Understanding FSL Teacher Demand}

FSL programs in schools fall into two main categories: mandatory programs for students in grades 4 through 9 and discretionary programs offered by boards that must meet Ministry of Education parameters based on the amount of instruction in French, (such as French Immersion, Extended French, Intensive French), but can begin and end at any grade.

As such, the demand for FSL teachers is often a direct function of the range of FSL programs offered in a board. Similarly, the demand for FSL teachers can fluctuate with a board depending on the types of discretionary programs offered, the proportion of instruction offered in French (beyond the Ministry minimum), and the grade levels where the programs begin and end. For example, a school board offering many discretionary FSL programs where the proportion of French instruction is more than the Ministry minimum across many grade levels, will de facto, require more FSL teachers than a board with a smaller range of programs with less instruction in French.

The survey revealed three key findings.

1. About $90 \%$ of school boards in Ontario offer at least one discretionary FSL program (usually French Immersion);

2. Because of the instructional time requirements for discretionary French instruction programs (e. g., 50\% of the school day for French Immersion), these programs currently require nearly twice as many FSL teachers than the mandatory French instruction programs (known as Core French); and

3. Most school boards currently require many more FSL teachers (approximately 5 times more) for all program types in the elementary grades than in secondary grades.

The relative demand for FSL teachers in Ontario (Figure 2) is shown according to the student enrolment in the range of FSL programs offered by school boards as of September 2017.

Secondary: Discretionary Intensive, Extended, Imm ersion

Secondary: Mandatory Core FSL

Elementary:

Discretionary Intensive, E xtended, Immersion

Elementary:

Mandatory Core FSL

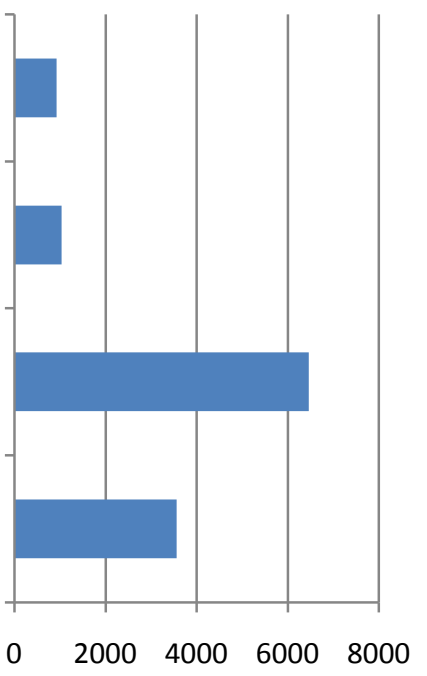

Figure 2. Numbers of FSL teachers needed to satisfy program demand 
It should be noted, however, that student enrolment must be combined with program type to generate a truer picture of FSL teacher demand. Mandatory FSL programs are most often delivered as a discrete subject, much like math or science, requiring approximately 40 minutes of instruction per day. Discretionary programs are most often variations of French Immersion, with French being the language of instruction for many or all subject disciplines. Minimally, these programs offer French instruction half the school day. When compared by instructional time, discretionary programs require approximately three times more teachers for the same number of students than do mandatory French programs. Explained another way, teaching FSL 40 minutes per day represents approximately $13 \%$ of the instructional day whereas teaching French immersion at a minimum requires $50 \%$ of the teacher's day, a factor difference of 3.8.

What is important to note is that the current FSL teacher demand in discretionary programs relative to demand in mandatory programs is augmented by persistent growth of discretionary French programs in Ontario over the past ten years. Enrolment statistics for French Immersion programs in particular have shown an annual average 5\% increase, with several large suburban boards reporting increases between 10 and 15\% (Canadian Parents for French, 2016). As such, the need for FSL teachers is concentrated in discretionary FSL programs offered by boards in response to public demand, programs that require considerably higher instructional time in French to meet Ministry requirements.

FSL Teacher Supply - Internal. The internal supply of FSL teachers includes those currently qualified to teach in FSL programs and currently employed in Ontario school boards in a variety of capacities:

- as contract teachers (full-time or part-time);

- as Long Term Occasional teachers;

- as Occasional Teachers; and,

- as teachers with Temporary Letters of Approval (i.e., without FSL qualifications) teaching in any of the above-mentioned capacities.

Under Ontario Ministry of Education Regulation 183, teachers of any French as a second language program in Ontario, mandatory or discretionary, must hold minimum qualifications in FSL pedagogy in addition to the qualifications of their counterparts teaching English only. These qualifications can be earned in one of three ways: as part of a teacher's basic teacher education program in some Faculties of Education according to their respective program requirements; as an Additional Qualification course in FSL granted by the Ontario College of Teachers but offered by a number of course providers in Ontario (may include Faculties of Education, teacher federations, individual school boards); and, as granted by the College of Teachers following a review of a teacher's credentials earned outside of Ontario.

Additionally, teachers may be granted a Temporary Letter of Approval from the Ministry of Education to teach a program for which the teacher does not hold required qualifications. These Letters expire at the end of each school year, and must be re-submitted annually as required. As such, the term "FSL teacher" must be understood to mean a teacher with FSL qualifications.
Satisfying the need for qualified FSL teachers is a complex, dynamic process that was difficult to express numerically. Nevertheless, Table 1 represents the number of FSL teachers across the province in the supply pipeline in various capacities as reported by participating school boards.

Table 1. Breakdown of FSL Teacher Need vs. Supply

\begin{tabular}{lcc}
\hline & Elementary & Secondary \\
\hline FSL Teacher Need & 10,023 & 1954 \\
*Occasional Teacher pool & 3226 & 1175 \\
*Long-term Occasional Teacher pool & 899 & 421 \\
**Teaching FSL <50\% of assignment & 1889 & 417 \\
(count as 0.5) & & \\
**Teaching no FSL in current & 2185 & 519 \\
assignment (count as 0) & 5268.5 & 1820.5 \\
Total FSL Teacher Supply & -4755 & -133.5 \\
Difference between Need and Supply & & \\
\hline
\end{tabular}

*FSL teachers in Occasional Teacher pools, or in Long Term Occasional pools, or even with Letters of Approval, are not mutually exclusive categories. Teachers in one group are also permitted to be in either or both of the other two groups both within a single board and across other boards. These numbers, therefore, need to be viewed with caution as they are likely to over-represent the number of teachers in any one group available to an individual school board, and therefore the capacity of these groups to supply non-contract teachers to fill French teacher vacancies in schools across the province.

**It is necessary to explain how FSL teachers come to teach French less than full-time, or not at all. As shown earlier, some FSL programs, such as mandatory Core, require fewer teachers than many discretionary programs due to the relatively smaller amount of French instructional time required by the program. Smaller schools may require only a half-time FSL teacher to accommodate their French program needs. It is commonplace for such a teacher to complete their teaching assignment by teaching subjects other than French. It is also commonplace for FSL qualified teachers to explore other teaching assignments for which they are qualified as part of their personal career development. When asked why contract FSL teachers would be teaching French less than $50 \%$ of their assignments, surveyed HR officials reported the top 3 reasons were:

1. school factors (e. g., staffing requirements, school size, student enrolment - strong factor weighting);

2. teacher factors (e. g., assignment choice, skill and comfort level using French - strong factor weighting); and

3. board factors (e. g., collective agreements, seniority, changes in FSL program design/location - moderate factor rating).

It must be noted here that the total number of teachers in Ontario with FSL teaching qualifications cannot be viewed as the overall supply. Data from the Ontario College of Teachers indicates that close to 32,000 members hold FSL teaching qualifications, a number well beyond what school boards currently report is needed to satisfy demand. College membership includes a wide spectrum of teachers working in many other capacities (e. g., school administration, consultation, Ministry of 
Education, teacher education programs, the College itself, among others) leaving them essentially unavailable to be considered part of the FSL teacher supply chain. Similarly, data from this survey indicates large numbers of FSL teachers teaching FSL half-time or not at all, largely due to teacher, school and board factors as identified above.

FSL Teacher Supply - External. Supplying sufficient numbers of FSL teachers to school boards also involves hiring additional new teacher graduates in order to increase the existing FSL teacher complement and address the shortfall identified in Table 1 . New FSL teachers are hired primarily from Ontario Faculties of Education, but can also include those FSL teachers who have earned their qualifications elsewhere in Canada and internationally. As noted above, many contract FSL teachers make professional decisions that remove them from the FSL teacher supply chain that, in turn, creates a continuous need to recruit new FSL teachers. This section reports on how such FSL teachers are recruited and the results of this yearly process.

School boards reported a notable drop (54\%) in the number of applications received from FSL teacher graduates over the past three years (Table 2).

Table 2. Number Of Job Applications By FSL Teacher-Graduates

\begin{tabular}{ccc}
\hline $\mathbf{2 0 1 5}-\mathbf{2 0 1 6}$ & $\mathbf{2 0 1 6 - 2 0 1 7}$ & $\mathbf{2 0 1 7 - 2 0 1 8}$ \\
\hline 8130 & 6697 & 3767 \\
\hline
\end{tabular}

These numbers account for multiple job applications submitted by individual teacher-graduates across multiple school boards in a given year. However, the decreased number of applications corresponds closely to a significant overall drop in applications to Ontario Faculties of Education following the introduction of the new 4-semester, teacher education program in 2015 [20].

Given that new FSL teacher recruitment is an annual process, changes to the yearly number of graduates has had an immediate impact on the number of teachers available to enter the FSL teacher pipeline. Data provided by the Ontario College of Teachers similarly shows that between 2015 and 2016, the number of teacher graduates earning FSL qualifications during their teacher education programs fell approximately $60 \%$ and the number of graduates earning FSL as an Additional Qualification post-graduation decreased by approximately forty per cent.

School boards were also asked to compare the FSL teacher supply-demand situation in their respective boards in recent years. Two-thirds of boards report that their efforts to satisfy their demand for FSL teachers has become more or much more challenging over the past three to five years, with no boards reporting the challenge has diminished. When asked which factors weigh most heavily on their ability to hire FSL teachers to fill vacant positions, boards identified, in order of significance:

- the overall low number of applicants;

- the number of times individual jobs must be posted before securing a suitable applicant;

- applicants' insufficient proficiency in French; and

- the increasing demand for FSL programs.

Boards identified the low number of FSL teacher applicants as having the greatest impact on satisfying their need for FSL teachers. This finding corresponds to the lower overall numbers of teacher education applicants, FSL job applications, and FSL jobs offered. Boards commented on the related challenge of having to post the same FSL positions multiple times in order to find suitable applicants. This led one board to comment, "we conduct continuous, year-round intake interviews for FSL teachers" rather than waiting for FSL job vacancies to appear.

School boards were asked to reflect on the effectiveness of their current FSL teacher recruitment strategies. In relative terms, strategies found to be effective included hiring FSL teachers into a pool, conducting French language assessments prior to job interviews, and actively recruiting soon-to-graduate FSL teacher candidates at university-sponsored job fairs. Less effective strategies include conducting online interviews or providing financial/in-kind incentives to applicants. Boards also noted that their use of specific recruitment strategies is affected by a number of local factors, for example, accurately predicting the anticipated number of FSL teachers needed year over year, or capitalizing on preestablished arrangements with Faculties of Education at a local university. These local factors may, therefore, affect how individual boards evaluate the effectiveness of recruitment strategies listed here.

French Language Proficiency. Related to the supply of new FSL teacher graduates and the number of external FSL teacher applicants, is the question of language proficiency in French. Language pedagogy researchers have made the case for FSL teachers to possess high levels of language competence to optimize their effectiveness teaching a second language $[5,21]$. As such, school boards were asked if they include an assessment of FSL teacher applicants' French language skills as part of their recruitment and hiring processes. Eighty-seven percent indicated they typically conduct an assessment of some, but seldom all, of applicants' speaking, listening, reading and writing skills in French. Table 3 shows the frequency of assessment methods used by boards to evaluate various components of applicants’ French proficiency.

Table 3. Frequency Of Methods Used By Boards To Assess Applicants' French Language Proficiency

\begin{tabular}{lll}
\hline $\begin{array}{l}\text { Our board does not assess the French language } \\
\text { competency of teachers applying to FSL positions. }\end{array}$ & $7 \%$ \\
\hline $\begin{array}{l}\text { Applicants' written language is assessed by evaluating a } \\
\text { writing sample holistically (not using pre-determined } \\
\text { standards). }\end{array}$ & $29 \%$ \\
\hline $\begin{array}{l}\text { Applicants' oral language is assessed and evaluated } \\
\text { against external/international language standards. }\end{array}$ & $0 \%$ \\
\hline $\begin{array}{l}\text { Applicants' oral language is assessed and evaluated } \\
\text { against language standards determined by the board }\end{array}$ & $33 \%$ \\
\hline $\begin{array}{l}\text { Applicants' written language is assessed by evaluating a } \\
\text { writing sample against external/international standards. }\end{array}$ & $4 \%$ \\
\hline $\begin{array}{l}\text { Applicants' written language is assessed by evaluating a } \\
\text { writing sample against language standards determined by }\end{array}$ & $24 \%$ \\
the board. & \\
\hline $\begin{array}{l}\text { Applicants' oral language is assessed during an interview } \\
\text { and evaluated holistically (not using pre-determined } \\
\text { standards). }\end{array}$ & $82 \%$ \\
\hline $\begin{array}{l}\text { Applicants complete an oral and written language } \\
\text { assessment developed by the board but evaluated against } \\
\text { internationally recognized French language proficiency }\end{array}$ & $4 \%$ \\
\hline $\begin{array}{l}\text { levels. } \\
\text { Applicants must show results from the Diplome d'etudes } \\
\text { en langue francaise or similar international assessment } \\
\text { tool. }\end{array}$ & $4 \%$ \\
\hline
\end{tabular}


There was considerable variation in the assessment practices across boards with many (80\%) focusing heavily on assessing applicants' oral (listening and speaking) language skills holistically (i. e., not measured against predetermined standards) during a job interview setting. Approximately $30 \%$ of boards measured applicants' oral French skills against standards developed by the board itself, while fewer boards (4\%) engaged applicants in a more comprehensive assessment process rating their oral French against an international French language assessment tool such as the Diplôme d'Études en Langue Française (DELF). For written language skills, more boards (24\%) were inclined to use board-determined standards to assess applicants, with approximately $4 \%$ using international standards to measure writing skill in French.

Nearly $10 \%$ of boards indicated they do not assess the French language skills (oral or written) of any FSL teacher applicants. Regardless of the degree or type of French language assessment used when recruiting external teacher applicants, boards who used an assessment protocol for FSL teacher applicants reported that an average of $27 \%$ of applicants did not meet their language proficiency thresholds and therefore were not considered for FSL teaching jobs.

\subsection{Summary of Findings from Human Resources}

In summary, data reported by school boards from a human resources perspective revealed the following key findings regarding FSL teacher supply and demand:

1. The increasing demand for FSL teachers is driven by an increase in the number of FSL programs that require high levels of instructional time in French (minimally, 50\% of the day). While these programs are discretionary, they have expanded significantly in the past ten years due to parent demand.

2. Quantifying supply and demand of FSL teachers is complex, and influenced by many dynamic factors such as fluctuating demand for programs, teacher choice in teaching assignments year to year, changing graduation rates of new FSL teachers, rates of current teachers acquiring necessary FSL teaching qualifications, and questions about new teachers' French language skill readiness for the job market.

All factors considered, the challenge in satisfying the annual demand for FSL teachers in Ontario remains a real and growing concern for school boards.

\subsection{Key Findings - Perspectives from Recently Hired FSL Teachers}

Much of the research on the FSL teaching experience stems from studies of teachers with considerable experience in the field, but little research has captured the experiences of FSL teachers in their transition years to teaching. Studies in the US have reported that teacher attrition in the early years is higher than at any other point in teachers' careers [3] with numbers reaching 50\% of teachers in their first 5 years leaving or considering leaving the profession [2].
In conditions of high teacher demand as in the case of FSL teachers, such teacher attrition rates would be of significant concern. As such, an online survey was developed to gather the impressions from first and second year FSL teachers of their recruitment, hiring and transition experiences into the role. Respondents were new teachers to FSL, including recent graduates, full-time or part-time, contract or occasional, and teachers new to FSL but with teaching experience in other contexts/subjects.

The online survey was distributed to all teachers in English-language school boards in Ontario working in their first or second year teaching FSL in some capacity. In total, 384 teachers responded to the survey. It was not possible to determine the total number of teachers eligible for this survey, so a reliable response rate cannot be reported as only those eligible FSL teachers currently employed would have received communication about the survey.

The survey was organized in three sections: 1) becoming an FSL teacher; 2) getting hired; and 3) the early phase of teaching. Focus groups were also organized at 7 different locations across the province to explore in greater depth the same topics covered in the survey. While 28 new FSL teachers initially expressed interest in the focus groups, logistics and inclement weather lowered the total participation number to eight in five locations with some groups operating as interviews between the facilitator and only 1 participant. This section reports on key findings from the survey and focus groups/interviews. Findings stemming from the focus groups/interviews must be interpreted with caution given the low response rate.

\subsection{Becoming an FSL Teacher}

Like many professional careers, teacher education programs usually include a period of post-secondary education before candidates formalize their decision to become a teacher. Some teacher education programs, including concurrent programs, admit students out of secondary school (e. g., Queen's University, York University) and provide earlier access to on-the-job experience for would-be teachers to finalize their teaching career choice. It was important to inquire about aspiring FSL teachers' motivations to pursue a career that, for most, included the challenge of gaining proficiency in French. As such, new FSL teachers were asked questions about their personal motivation in pursuing FSL as a career and the factors influencing the development of their language proficiency in French. Table 4 shows their responses in order of frequency:

Table 4. Motivators In Pursuing FSL Teaching And Influences In French Language Learning

\begin{tabular}{ll}
\hline $\begin{array}{l}\text { Top Motivators in pursuing FSL } \\
\text { teaching }\end{array}$ & $\begin{array}{l}\text { Strongest influences on } \\
\text { developing French language } \\
\text { proficiency }\end{array}$ \\
\hline 1. Healthy job market (56\%) & $\begin{array}{l}\text { 1. Learning French in school } \\
(71 \%)\end{array}$ \\
2. Opportunities to continue using & $\begin{array}{l}\text { 2. Engaging with broader } \\
\text { French (47\%) }\end{array}$ \\
$\begin{array}{l}\text { 3. Enjoyed learning French in school } \\
\text { (41\%) }\end{array}$ & $\begin{array}{l}\text { French-speaking community } \\
\text { 4. Personal experience where knowing }\end{array}$ \\
French was an advantage (37\%) & friends (42\%) \\
\hline
\end{tabular}


Some teachers mentioned other motivators, such as expected job satisfaction, but markedly less frequently than those reported. Learning French in school was a much stronger influence (94\% reported it as having Some or Significant Influence) than either engaging with French speakers or family and friends (78\% and $74 \%$ respectively). This ranking, however, may also reflect teachers' lack of opportunity to engage with French speakers or family/friends in ways that could meaningfully influence their language learning.

New FSL teachers also reported that $55 \%$ of them earned FSL credentials as an Additional Qualification; $38 \%$ earning their credentials during their teacher education program with the balance of teachers awarded FSL qualifications assessed by the Ontario College of Teachers based on other related education and professional credentials. Approximately $2 \%$ of teachers reported teaching FSL without FSL qualifications.

\subsection{Getting Hired}

The second part of the online survey explored the under-researched area of FSL teacher recruitment and hiring. In an effort to understand job-seeking behaviour better, questions centred on how teachers look for FSL job opportunities, the factors influencing where they do and do not apply, how many boards they apply to, and their impressions of various elements of the job interview process.

Most new FSL teachers reported they learned about available jobs through school board websites, by knowing current employees of the board, and through conversation with colleagues and other applicants. When asked about the factors influencing their decision to apply to particular boards, new FSL teachers identified that board's proximity to their preferred place of residence as the strongest influence, followed by their prior knowledge of the board and experience working in the board as a volunteer or as part of their teacher education practica. Thirty-six percent of new FSL teachers applied to only one school board for work, with sixty percent applying to 2 to 5 boards, and only four percent applying to more than 5 boards. Comments gathered through the focus groups indicated that many new FSL teachers target a few, specific school boards due to the boards' location or reputation. These data may not be surprising in light of the persistently strong demand for FSL teachers, and may differ from the job-seeking strategies used by teachers in a more competitive job market.

The next section of the survey explored the job interview in particular, a practice used by all school boards when hiring teachers. New FSL teachers reported very similar interview processes: submission of required documentation, an in-person interview (15\% reported an online component supplemented the in-person component), and post-interview communication online or in person (20\% reported no form of post-interview communication). Additionally, most new FSL teachers engaged in some form of French language assessment as part of the interview process. Approximately half of the time, the language assessment was conducted in-person before, during or after the interview. About one quarter of French language assessments were conducted using a combination of online and in-person components, with $10 \%$ of new FSL teachers reporting their French language assessment was conducted online only. Ninety-six percent of new FSL teachers were invited for job interviews with approximately $85 \%$ attending most of the interviews granted.

New FSL teachers were asked to rate various elements of the interview process and provide reflections on their overall experience. The interview venue and disposition of the interview team, opportunities to ask questions, and the experience with the French language assessment all generated positive ratings. New FSL teachers were less favourable in their rating of the interview feedback process (little opportunity, or generally too superficial), and with the lack of clarity of expectations provided prior to the interview itself. Additionally, new FSL teachers were asked to identify specific challenges that dissuaded them from pursuing a teaching job with a specific board at any point in the recruitment/hiring process. Most responses clustered around three key themes. These include:

1. Lack of specificity about available jobs. Some boards hire to a pool and may not be able to provide job specifics before expecting a candidate to accept a job offer; some very large boards are unable to determine at interview time where job openings will be within the board. Given the geographic size of some Ontario boards, school sites may be an hour's drive from each other.

2. Location of interviews. Some boards arrange interviews on their premises only. If interview locations are geographically distant from where applicants live, they may not be able to manage the travel time needed to accommodate interviews during the work week, especially since many new FSL teachers are still teacher candidates in university at the time of job interviews.

3. Timing of job applications and interviews. Often, collective agreements between school boards and their teacher unions govern teacher-hiring timelines. If applicants are eager to secure a job early, then they will accept offers from boards made early in the hiring cycle, but continue searching throughout the cycle for a preferred job elsewhere.

The conditions leading to the challenges identified above are complex but may be of interest in school boards where the recruitment of FSL teachers has been most problematic.

\subsection{Early Phase of Teaching FSL}

The final topic explored with new FSL teachers focused on their impressions of FSL teaching up to the time of this study. Their experience ranged from being in their second year teaching full-time, to teaching only a few weeks in a long-term occasional assignment. Similarly, some new teachers were teaching only FSL during this time while others were teaching less than half their assignment in FSL. Of those teachers teaching full-time, more than half taught French Immersion, approximately half taught Core French (as a subject), with the balance teaching a combination of the two programs.

New teachers were then asked about their confidence in teaching FSL and the rewards and challenges encountered 
at this early phase in teaching. Eighty percent indicated they were confident or very confident and identified the following rewarding experiences as contributing to their overall confidence:

- more than $1 / 2$ the respondents expressed pride in seeing students' linguistic development in French;

- about 1/3 mentioned being an advocate for French language and culture; and

- about $1 / 3$ said that being able to secure a teaching position was a reward in itself.

Approximately twenty percent of new teachers, however, indicated a lack of confidence in their FSL teaching. Focus group/interview participants elaborated on possible reasons contributing to lower confidence: lack of mentorship, isolation, unsatisfying practicum placements that left them unprepared, and overall communication skills in French. Such reasons are reflected in the following comments from three participants:

I became a French teacher in the elementary panel and not being familiar with the new curriculum until I walked into the job, I was severely underprepared and therefore exceptionally stressed out.

And for anyone to think that 3 PD sessions or even my AQs that I took are enough, are sufficient, for that?! [participant's rhetorical voice] It's such a complicated thing that we all know that teachers deal with extra problems of classroom management, challenging new curriculum coming in. There are so many layers of it.

Teacher's college did not prepare me as much as I would have liked, because I did Primary-Junior [grades $K-6]$, so there weren't really any opportunities to either practise French or build the French curriculum, because I chose PJ.

Recognizing that new teachers are likely to experience challenges transitioning into their careers, new FSL teachers were asked to identify challenges encountered at this point in their FSL teaching. The top three challenges listed were:

1. access to suitable teaching resources;

2. students' attitudes to learning French; and

3. readiness to support a range of diverse students.

Drawing from the abundance of literature on the potential positive effects of professional learning on teacher practice [22], we asked new FSL teachers what areas of professional learning they believed would be most beneficial at this point in their work. It was anticipated that a relationship might emerge between what FSL teachers identified as a professional challenge and their professional development needs. When asked to rank order their professional learning needs at this early stage of their careers, new FSL teachers identified the following top three:

1. availability of effective teaching resources;

2. pportunities to improve French language skills; and

3. knowledge of effective teaching strategies.

Potential links appear between the identified areas of professional challenge and desired professional learning:

- Effective teaching resources were identified as a challenge (65\%) and a strongly desired professional learning need (78\%); and,

- Opportunities to use/improve French skills emerged as a weaker, but noteworthy challenge (22\%) and desired area of professional development (44\%).
Given participants' responses, effective teaching resources and opportunities to improve French language skills appear to be top of mind for FSL teachers in their first or second year of teaching.

\section{French Language Proficiency}

The question of French language proficiency emerged as a concern in the comments included in the Human Resources survey of this study with school boards reporting approximately one in four FSL teacher applicants falling short of board's French proficiency thresholds. As such, new FSL teachers were asked to selfrate their skill as a French language user. The rating criteria were drawn verbatim from the global scales of the French CEFR (Common European Framework of Reference), a tool used increasingly in Ontario schools to guide the development of students' French language skills, as a vehicle for professional learning among FSL teachers, and in a limited number of teacher education programs to support language development of FSL teacher candidates [23].

The CEFR provides 6 categories of proficiency (A1 Beginner; A2 Elementary; B1 Intermediate; B2 Upper Intermediate; C1 Advanced; C2 Master or Proficient), each encompassing four key areas of language development. Additionally, FSL teachers could identify themselves as native speakers of French. For the purposes of this study, the basic categories A1 and A2 were not available as criteria choices. Figure 3 shows that approximately half of new FSL teachers rated their French proficiency in the Intermediate range, with the balance rating themselves as Advanced or Proficient (including French first language speakers).

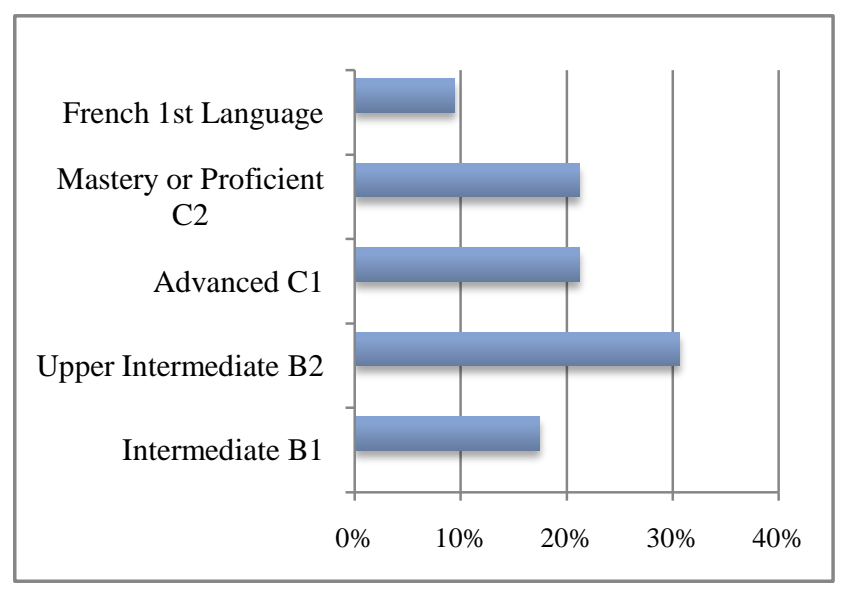

Figure 3. Distribution of self-ratings as French language users based on CEFR global scale descriptors

Because so few boards (4\%) reported using international standards such as the CEFR criteria to evaluate FSL teacher applicants' French proficiency, it is not possible to correlate the self-ratings of new FSL teachers' proficiency levels with board-by-board hiring thresholds. The final survey question asked participants to share additional comments and concerns regarding their recruitment, hiring and transition to teaching experiences. Alongside questions about available teaching resources, fidelity of French language use was the most frequently identified concern 
among new FSL teachers. This lack of board-to-board consistency seems to be a source of frustration among new FSL teachers. The following comments from survey and focus group participants illustrate this point.

The language proficiency tests boards give is all over the map. In one board, they asked me 1 question in French; in another, the entire interview was in French.

During my interviews, no one asked any questions IN [participant's emphasis] French.

I was shocked at the frequency of interviews where my French language skills were not evaluated. Although OTlist interviews had pre-screening in French, only about half of LTO interviews asked a question in French. In one case, the English translation of the question was written and provided.

There are a lot of inconsistencies between interviewers, and you don't really know what you are walking into in a particular interview. And there are some that are just basically like - I know when the person walks in the door, whether they are going to pass or not. And if they are not passing, I've got to come up with a way, something to say as to why they can't pass. So... It was, yeah. Frustrating. People are asking me, and "You know what, that person passed, that person passed. I don't know how they passed it."

And so speaking with other people was basically - if they came out of the interview thinking they passed, all excited about it - usually that meant that they didn't pass, and people who came out not really sure, usually those are the ones that ended up passing . . That's frustrating...and disconcerting, because you don't really know what you are being evaluated on.

It would be nice if there was some sort of common standard between the boards, whereas the [school] board didn't have enough French teachers to teach Core French, where this board said they did, and that's how I got my contract here. So some consistency between the boards of what is acceptable for each level. It was kind of a lowblow but after talking to my other French teacher friend, she said she had a tutor and she did French immersion her whole career as a student and she wasn't qualified enough for them...

\section{Research Summary}

Various stakeholders have documented a shortfall in the number of FSL teachers sufficient to meet demand in Ontario and other Canadian jurisdictions for at least the past thirty years. Previous studies that have pointed to the nature of the FSL teacher role explain in part the teacher attrition rates contributing to the shortage, but without comparisons to attrition rates among non-FSL teachers or due consideration of other factors affecting the FSL teacher supply pipeline. Very limited research was found that investigated the FSL teacher shortage from a labour market lens within the context of strong and long-standing job demand.

The present study explored the collective realities of 56 English-language school boards in their challenge to satisfy a persistent demand for FSL teachers in Ontario. This challenge is magnified by two related factors: the reported number of FSL teacher graduates who, while qualified, struggle to meet boards' French language proficiency thresholds, and more recently, the sharp drop in the number of FSL teachers graduating from Ontario Faculties of Education.

Survey and focus group findings in the present study suggest that the relationship between supply and demand of FSL teachers is a complex one with many variables impacting the number of teachers needed annually to provide sufficient numbers capable of undertaking the FSL teacher role. These variables include the dynamics of hard-to-predict teacher choice in their own teaching assignments and increasing demand for types of FSL programs that require proportionately more teachers.

Additional investigation of boards' HR practices identified only modest satisfaction with current FSL teacher recruitment efforts. Survey analyses showed wide variability in the methods used to assess the French language proficiency of FSL teacher applicants, a problematic phenomenon also noted by new FSL teachers' reflections on their personal hiring experiences.

The study also investigated the under-researched recruitment, hiring and retention realities of new FSL teachers. These teachers reported overall confidence in their ability to take on the FSL teacher role, but identified challenges with some elements of boards' recruitment and hiring processes that ultimately affected where they chose to apply and eventually work. They identified further challenges once working in the FSL teacher role that appear to match their desired areas of professional development: accessing effective teaching resources, and opportunities to develop their French language skills. New FSL teachers also identified factors that influence their decisions to apply or not apply to jobs in various school boards, and described elements of the recruitment and hiring experience that ease or frustrate their entry into the FSL teacher role.

\section{Questions for Future Investigation}

While reflecting on the analysis of the data uncovered during the present study, the FSL - Labour Market Partnership Committee raised a number of questions that could inform future research towards addressing the supply and demand for FSL teachers in Ontario. Such future research questions include:

- How are secondary school students motivated to pursue FSL teaching as a career choice?

- What are the career choices of secondary school graduates from French Immersion/Extended French programs?

- How has the introduction of the 4-semester teacher education program in Ontario affected the enrolment of particular groups of prospective teacher candidates, especially FSL teacher candidates?

- How is the FSL teacher supply and demand issue being explored in other parts of Canada? and,

- How are non-French speaking FSL teacher candidates supported in their French language proficiency development during their teacher education programs? 


\section{Overall Project Summary and Next Steps}

All member organizations and associations of the French as a Second Language-Labour Market Partnership have collaborated to support seven recommendations stemming from the research phase of the project. The recommendations emphasized two key areas of focus: FSL teacher recruitment, and FSL teacher retention and professional support. In November 2018, funding by the Ontario Ministry of Training, Colleges and Universities (previously the Ministry of Advanced Education and Skill Development) was approved for a second project phase in order that the Partnership begin the implementation process for all recommendations over the remaining two years of the project.

\section{Acknowledgements}

The funding for this Labour - Market Partnership Project was provided in part by the Government of Canada and the Government of Ontario. The efforts of many individuals have contributed to the work involved in completing this phase of the project. While some have represented the perspectives of a specific organization or association, each voice reflects genuine commitment to the mandate of the project: to ensure sufficient numbers of teachers are able to provide quality French as a Second Language (FSL) instruction to Ontario students. The views expressed in this report are the views of the Ontario Public School Boards' Association and do not necessarily reflect those of the Province of Ontario.

\section{References}

[1] Karsenti, T., Collin, S., Villeneuve, S., Dumouchel, G., \& Roy, N. (2008). Why are new French Immersion and French as a second language teachers leaving the profession? Results of a Canadawide survey, Canadian Association of Immersion Teachers, Ottawa.

[2] Liu, X., \& Ramsey, J. (2008). “Teachers' job satisfaction: Analyses of the Teacher Follow- up Survey in the United States for 2000-01", Teaching and Teacher Education, 24. 1173-1184.

[3] Guarino, C., Santibanez, L., \& Daley, G. (2006). "Teacher recruitment and retention: A review of the recent empirical literature”, Review of Educational Research, 76 (2), 173-208.

[4] Macfarlane, A., \& Hart, D. (2002). Shortages of French as a second language teachers: Views of school districts, faculties of education and ministries of education, Canadian Parents for French, Ottawa.

[5] Veilleux, I. \& Bournot-Trites, M. (2005). "Standards for the Language Competence of French Immersion Teachers: Is There a Danger of Erosion?” Canadian Journal of Education 28 (3). 487507.

[6] Canadian Parents for French (2017). The State of French Second Language Education in Canada 2017. Retrieved from: https://cpf.ca/en/files/State-of-FSL-Education-Report-FinalWeb.pdf.

[7] Clark, R. \& Antonelli, F. (2009). "Why Teachers Leave: Results of an Ontario Survey 2006-08”, Ontario Teachers’ Federation.

[8] Core French in Ontario Public School: OPSBA Survey of School Boards. (2007). Ontario Public School Boards’ Association.

[9] Teacher Supply and Demand Survey: Executive Summary. (2008). Ontario Ministry of Education Retrieved from:

http://www.edu.gov.on.ca/eng/policyfunding/memos/august2008/ TeacherSurvey.pdf.
[10] The Globe and Mail (2019, February 19). Shortage prompts school boards to hire teachers. Retrieved from:

https://www.theglobeandmail.com/.../article-school-boardsdesperately-short-of-frenc...

[11] The Globe and Mail. (2016, June 4). There's just one problem with French Immersion. Retrieved from: https://www.theglobeandmail.com/opinion/the...frenchimmersion/article30259804/

[12] Paikin, S. (2016, September 13). The Agenda. Retrieved from: https://www.youtube.com/watch?v=D2ObH5lEmr8.

[13] Obadia, A. (1989). "La crise est arrivée: la croissance des programmes de français langue seconde et ses répercussions sur la qualité et le nombre des enseignants”, Canadian Modern Language Review, 45 (3). 435-444.

[14] Arnott, S., Hart, D., Lapkin, S., Mady, C., Vandergrift, L., Masson, M-E. (2015). French as a Second Language in Canada: Potential for Collaboration, Council of Ministers of Education, Canada, Toronto.

[15] Kitchenham, A., \& Chasteauneuf, C. (2010). "Teacher Supply and Demand: Issues in Northern Canada”, Canadian Journal of Education, 33 (4). 869-896.

[16] Makropoulos, J. (2010). "Student attitudes to the secondary French Immersion curriculum in a Canadian context”, Language, Culture and Curriculum, 23 (1). 1-13.

[17] Lapkin, S., MacFarlane, A., \& Vandergrift, L. (2006). Teaching French as a Second Language in Canada: Teachers' Perspectives. Research Report co-published by the Canadian Teachers' Federation, the Canadian Association of Second Language Teachers, and the Canadian Association of Immersion Teachers.

[18] Kissau, S. (2005). "The Depreciated Status of FSL Instruction in Canada”, Canadian Journal of Educational Administration and Policy, 44. 1-21.

[19] Roy, S. \& Galiev, A. (2011). "Discourses on Bilingualism in Canadian French Immersion Programs”, Canadian Modern Language Review, 67 (3). 351 - 376.

[20] Ontario University Application Centre. (2018. March) Data Request from the Teacher Education Application Statistics: Proportions of Francophone and Bilingual French-English speakers in Canada. Statistics Canada, 2016. Retrieved from: http://www12.statcan.gc.ca/census-recensement/2016/rt-td/langeng.cfm.

[21] Bayliss, D., Vignola, M-J. (2007). Training Non-native Second Language Teachers: The Case of Anglophone FSL Teacher Candidates”, Canadian Modern Language Review 63, (3) 371-398.

[22] Campbell, C., Osmond-Johnson, P., Faubert, B., Zeichner, K., \& Hobbs-Johnson, A. (with Brown, S., DaCosta, P., Hales, A., Kuehn, L., Sohn, J., \& Steffensen, K. (2016). The state of educators' professional learning in Canada. Learning Forward, Oxford, $\mathrm{OH}$.

[23] Arnott, S., Brogden, L. M., Faez, F., Peguret, M., Piccardo, E., Rehner, K., Yaylor, S. K., Wernicke, M. (2017). "The Common European Framework of Reference (CEFR) in Canada: A Research Agenda”, Canadian Journal of Applied Linguistics, 20 (1). 31-54.

[24] Alphonso, C., Federal government commits funds to address shortage of French Immersion teachers. February 28, 2018. Retrieved from: https://www.theglobeandmail.com/news/national/education/school -board-to-offer-moving-allowance-to-lure-french-Immersionteachers/article38160331/.

[25] Fitzpatrick, M. (2017). 'We're doing the best we can': French Immersion teacher shortage in Canada a chronic and stressful problem. Retrieved from: http://www.cbc.ca/news/canada/canadafrench-Immersion-teacher-shortage-1.4423050.

[26] French as a Second Language Enrolment Statistics 2011-2012 to 2015-2016. Canadian Parents for French. Retrieved from: https://cpf.ca/en/files/Enrolement-Stats.pdf.

[27] Media Release, (2017, September 27). Another rise in French Immersion enrolment reflects the public's confidence in the program and support for official language bilingualism. Canadian Parents for French, Retrieved from: https://on.cpf.ca/wp-content/blogs.dir/1/files/Rise-in-FIenrolment-reflects-the-publics-confidence-in-the-program-andsupport-for-official-language-bilingualism-September-2017.pdf. 
[28] Obadia, A. A., \& Martin, M. (1995). "FI teacher shortage: Seeing the light at the end of the tunnel”, The Canadian Modern Language Review, 52. 81-100.
[29] The Ontario College of Teachers (2006). Transition to Teaching Report 2006. Toronto, ON.

(C) The Author(s) 2019. This article is an open access article distributed under the terms and conditions of the Creative Commons Attribution (CC BY) license (http://creativecommons.org/licenses/by/4.0/). 